\title{
Antibodies against reticulin and collagen
}

\author{
E. J. HOLBOROW, W. PAGE FAULK, HELEN K. BEARD, ANd L. B. CONOCHIE \\ From the MRC Rheumatism Unit, Canadian Red Cross Memorial Hospital, Taplow, Bucks
}

Nowadays the idea that systemic rheumatic conditions such as rheumatoid arthritis, systemic lupus erythematosus, and scleroderma are disorders primarily affecting collagen-that is, that these conditions are 'collagen diseases'-has been somewhat discredited. Fifteen to 20 years ago it attracted considerable support from the then striking revelation that autoimmunity directed at certain tissue antigens not only occurs but may be closely associated with local disease in organs where the antigens in question are found. Endocrine autoimmune diseases such as Hashimoto's thyroiditis are classic examples.
It has turned out, however, at least in SLE and rheumatoid arthritis, that while it cannot be seriously doubted that autoantibodies do indeed make a major contribution to the pathogenesis of the typical arthritis, nephritis, or vasculitis reactions respectively they do so by their participation in the formation of immune complexes in which the antigens involved, although endogenous, are demonstrably not exclusively characteristic of the tissue sites affected. At least a significant part of the damage results from the inflammatory consequences of local deposition of immune complexes.

The demonstrable immunogenicity of collagen

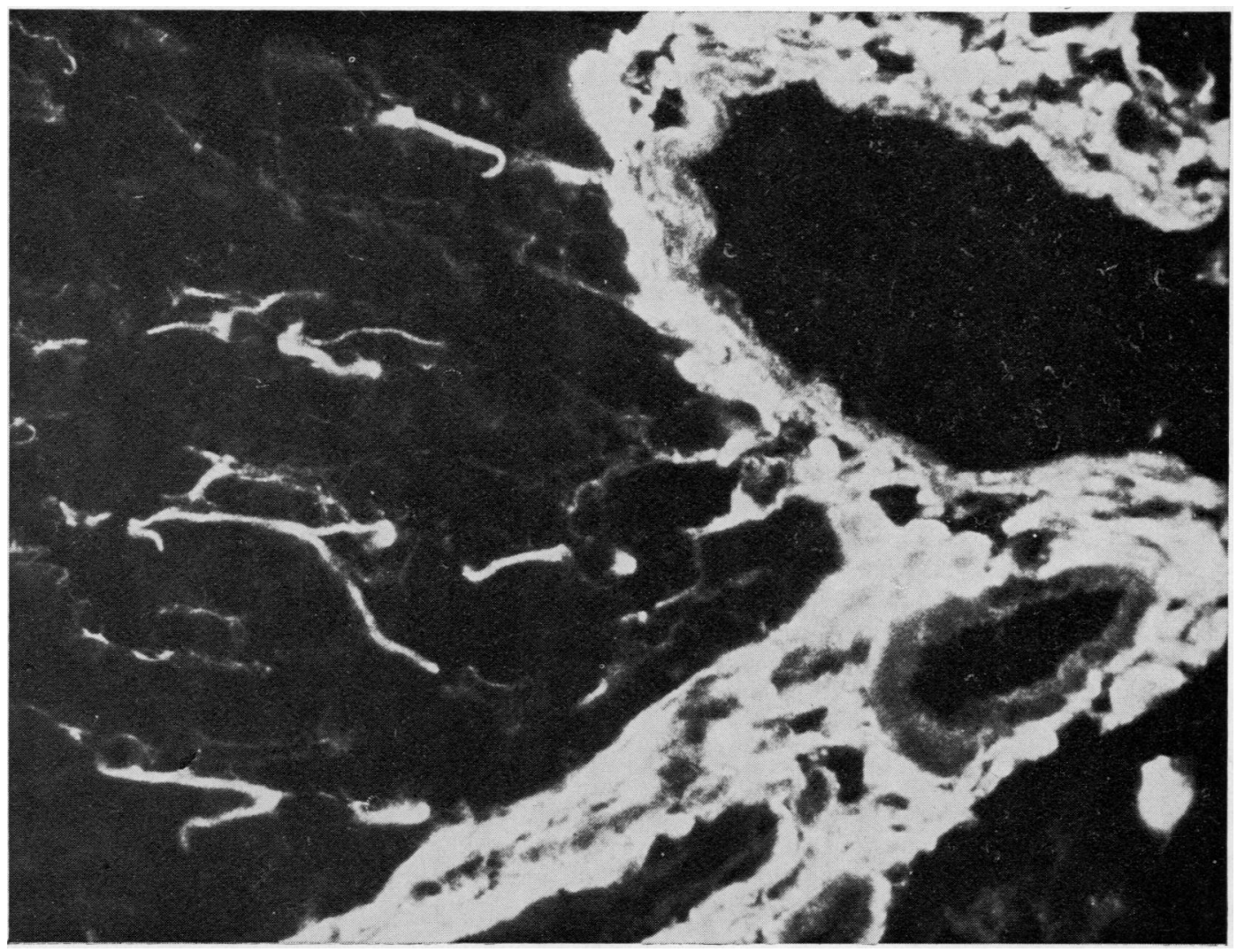

FIG. 1 Cryostat section of rat liver. Staining of adventitial fibres in a portal tract and fibres in the parenchyma produced by serum from patient with coeliac disease. Indirect immunofluorescence. $\times 320$ 


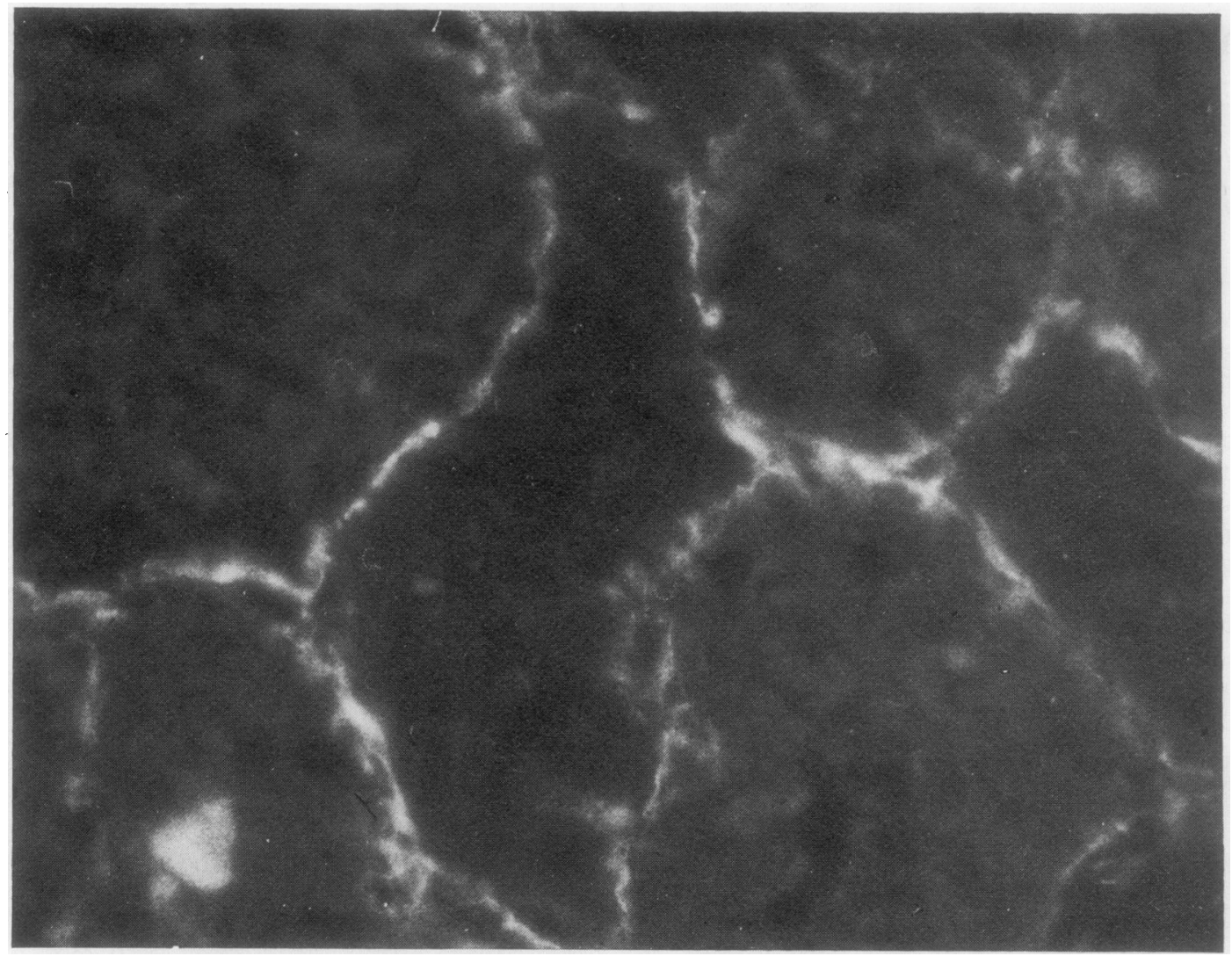

FIG. 2 Cryostat section of rat kidney. Staining of peritubular and periglomerular fibres produced by same serum as in Fig. 1. $\times 320$

when injected into experimental animals refutes the early view that collagen is a non-antigenic substance, and the striking antigenic differences which have recently been shown to exist between the native and denatured forms of collagen molecules have refocused attention on the possibility that collagen may be an autoantigen in man. At the same time immunological observations in human gastroenterology and dermatology have indicated that another connective tissue component, reticulin, may also acquire autoantigenic properties, since antireticulin antibodies are found in coeliac disease, dermatitis herpetiformis (DH), and Crohn's disease.

This communication compares and briefly contrasts the autoantibodies found in man against these two connective tissue components-that is, reticulin and collagen-and considers some of the ideas that have been put forward to account for their presence and, indeed, to ascribe to them a functional significance.

\section{Antireticulin antibodies}

One of the most striking immunological abnormalities in gluten-sensitive enteropathy is the presence of autoantibodies that give an immunofluorescence staining pattern similar in distribution to that of reticulin (Figs. 1, 2). Their highest incidence, about $85 \%$, is in coeliac disease in children who are not on a gluten-free diet (Seah et al., 1973). The sera of $60 \%$ of adults with untreated coeliac disease patients and $30 \%$ of patients with untreated DH also react by immunofluorescence with connective tissue fibres in cryostat sections of various organs from rats, humans, and other species. The best correlation of the immunofluorescence pattern is with the distribution of staining by silver impregnation. Since collagen stains yellow, brown, or pink by this method and reticulin stains black this suggests that the antibody in these patients' sera is antireticulin. The failure of pretreatment of sections with collagenase to affect their ability to display the characteristic staining pattern with these sera while removing their ability to stain by van Gieson's method supports this idea. Immunoperoxidase visualization of the antibody in the electron microscope shows that matrix not collagen is stained (Fig. 3).

F Reticulin is the name given to a particular 


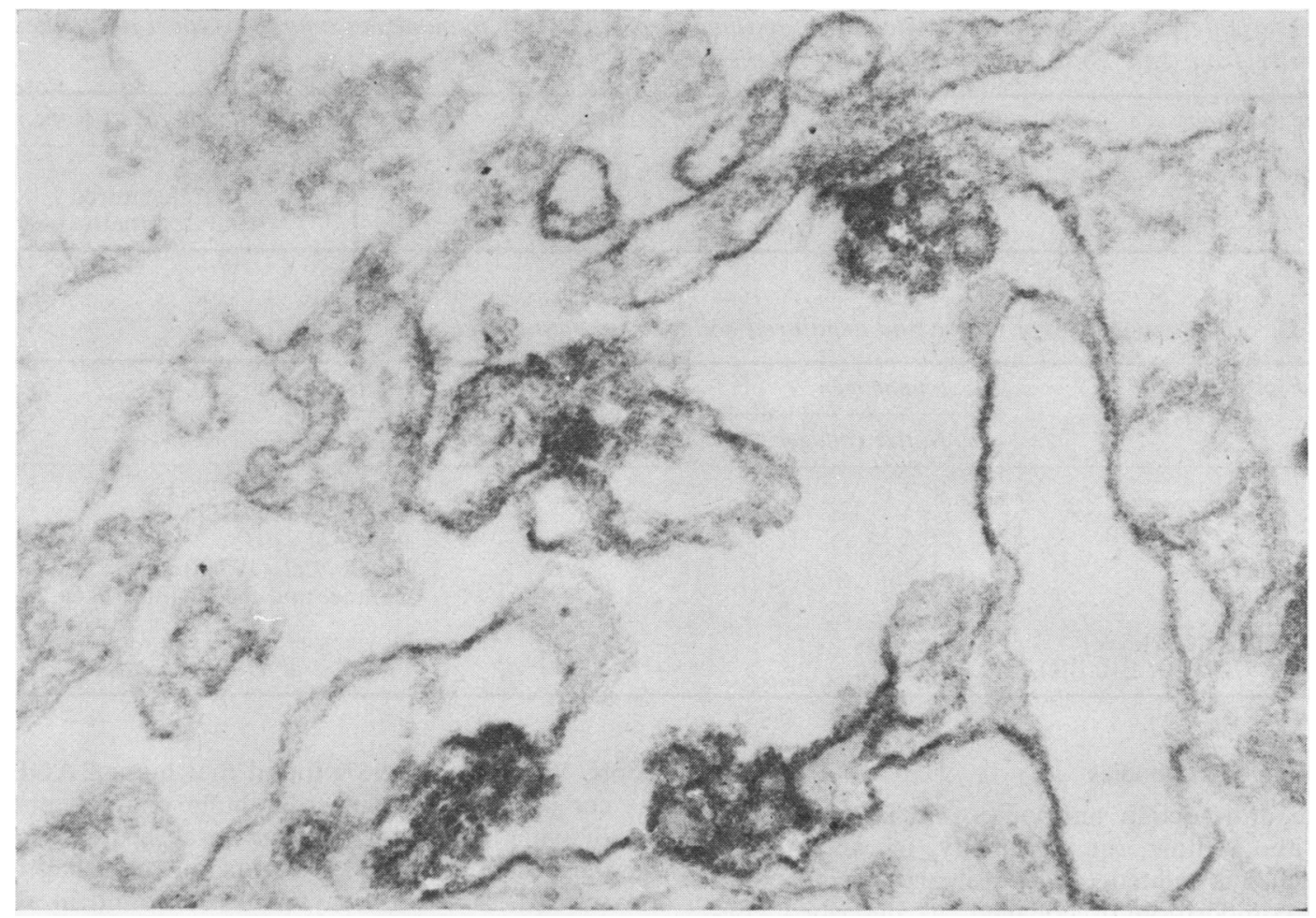

FIG. 3 Electron micrograph showing cross sections of collagen fibres in a rat liver preparation treated with human serum containing antireticulin antibody. Note no staining of fibres but perifibrillar zones show positive staining. Immunoperoxidase method. $\times 62000$. (Kindly provided by Dr. P. P. Seah)

histological form of extracellular connective tissue fibres that are fine, branched, and isotropic between crossed polars. They are unstained by van Gieson dyes and are blackened by silver impregnation techniques. Reticulin thus differs antigenically as well as histologically from collagen, as suggested by Taylor et al. (1961), and this conclusion receives support from the observation that a non-collagenous reticulin component could be extracted from the saline insoluble residue of pig or human renal cortex or liver. The extract contains no hydroxyproline but is $4 \%$ carbohydrate and is antigenic in rabbits (Pras and Glynn, 1973). The resulting antiserum gives a fluorescent staining pattern on cryostat sections indistinguishable from that obtained with human antireticulin antibody. Furthermore, the non-collagenous reticulin component of Pras and Glynn proved to be capable of absorbing the characteristic staining pattern imparted by human antireticulin antibody from 9 out of 11 sera tested (Pras et al., 1974). It was also noted that human antireticulin antibody does not stain the argyrophilic fibres of the newly formed collagen fibres seen in healing wounds, and this is probably due to the absence of a specific glycoprotein of reticulin from young collagen fibres in this situation. So far, however, the chemical nature of the antigenic determinants specific for reticulin has not been elucidated.

The reasons for the appearance of antireticulin antibodies in gluten enteropathy and their possible immunopathological significance are obscure. Their appearance may result from increased absorption of bacterial and food antigens in malabsorption states, and a report of raised antireticulin titres in heroin addicts may reflect a connexion with micro-organisms (Rizzetto and Doniach, 1973). This would put them in the class of autoantibodies such as smooth muscle and antinuclear antibodies which are more easily evoked by external agents such as viruses and drugs.

It is tempting to attribute the $\mathrm{Ig}$ and complement deposits found in the reticulin-rich dermal papillae in $\mathrm{DH}$ to the reaction of these antibodies, but neither these nor the immune complexes demonstrated in sera of both coeliac disease and DH patients (Mowbray et al., 1973) have yet been linked with the presence of antireticulin antibodies. 
Table I Different specificities of anticollagen antibodies produced by immunizing animals (type I antibodies composite from rat, guinea-pig, rabbit, and chicken)

\begin{tabular}{|c|c|c|}
\hline Species specificity & Molecular region of determinants & Antibody reacts with \\
\hline Species specific & $\begin{array}{l}\text { Helical (conformation dependent) } \\
\text { Non-helical (sequence dependent) }\end{array}$ & $\begin{array}{l}\text { Native } \\
\text { Native, denatured }\end{array}$ \\
\hline
\end{tabular}

Table II Immunogenicity of native and denatured collagen in animal species

\begin{tabular}{|c|c|c|c|}
\hline \multirow[t]{2}{*}{ Animal species } & \multicolumn{2}{|l|}{ Immunogen } & \multirow[t]{2}{*}{ Authority } \\
\hline & Native collagen & Denatured collagen & \\
\hline Rabbit & + & + & $\begin{array}{l}\text { Lindsley et al. (1971) } \\
\text { Beil et al. (1973) }\end{array}$ \\
\hline $\begin{array}{l}\text { Chicken } \\
\text { Guinea-pig }\end{array}$ & $\begin{array}{l}+ \\
+\end{array}$ & \pm & $\begin{array}{l}\text { Beil et al. }(1973) \\
\text { Beard } \text { et al. }(1976 a) \\
\text { Gentner and Adelmann }(1976 a, b)\end{array}$ \\
\hline $\begin{array}{l}\text { Mouse (SWR; C3H.SW) } \\
\text { Mouse (C57BL/10; B10.BR) }\end{array}$ & $\begin{array}{l}+ \\
+\end{array}$ & \pm & $\begin{array}{l}\text { Nowack et al. (1975) } \\
\text { Fuchs et al. (1974) }\end{array}$ \\
\hline
\end{tabular}

\section{Anticollagen antibodies}

Unlike antireticulin antibodies, we know a good deal about how the specificity of anticollagen antibodies is related to the primary structure and chain composition of collagen, as described elsewhere in this symposium. In the native molecule the triple-helical conformation is maintained throughout its length except for short, non-helical regions at both ends. The native conformation is lost on gentle heating and the resulting chains of denatured collagen assume random conformations as mono-, di-, or trimeric forms. Immunization of different animal species with heterologous collagen produces specific antibodies whose specificity varies according to the native or denatured state of the antigen (Tables I, II) and according to the species of animal immunized (Beard et al., 1976a).

\section{Anticollagen antibodies in disease}

Humans have antibodies to denatured collagen (called antigelatin factor (AGF)) in their sera (Maurer, 1954), but recent attempts to measure human autoantibodies to collagen in health and disease have produced conflicting results concerning the presence of anticollagen antibodies in normal people. Wolff et al. (1967) found that human AGF was composed of two macroglobulin components, one of which (the 'agglutinator') was heat labile. They suggested that AGF differs from true collagen antoantibodies in three ways: (1) it is found in all sera, (2) it is heat labile, and (3) it is macroglobulin in nature. Maurer (1954) found AGF in $65 \%$ of human sera and he was the first to report that these antigelatin antibodies were indeed heat labile (Maurer, 1958). However, Beard et al. (1976a) found heat stable agglutinators in all of a large number of normal human sera tested (Table III) which react with denatured human collagen in passive haemagglutination.

These findings conflict with those of several other authors, who report antigelatin antibodies in no more than $10 \%$ of normal sera using either passive haemagglutination (Wells et al., 1973; Hahn et al., 1975; Michaeli and Fudenberg, 1974b) or the antiglobulin consumption test (Steffen, 1969, 1970), although it is not always stated in these reports whether or not the sera were heated. Unlike others (Wells et al., 1973; Michaeli and Fudenberg, 1974a, 1974b), we (Beard et al., 1976a) used unformalized tanned red blood cells in passive haemagglutination, and direct comparison of fresh and formalized

Table III Reported incidence of anticollagen antibodies in normal human subjects

\begin{tabular}{clll}
\hline Positive (\%) & Native & Denatured & Authority \\
\cline { 2 - 3 } \cline { 4 - 5 } $2 \cdot 5$ & + & - & Wells et al. (1973) \\
1.0 & + & - & Michaeli and Fudenberg (1974a) \\
$9 \cdot 0$ & + & - & Michaeli and Fudenberg (1974b) \\
$56 \cdot 0$ & - & + & Conochie and Faulk (unpublished) \\
$100 \cdot 0$ & & Conochie and Faulk (unpublished) \\
\hline
\end{tabular}


tanned red blood cells in haemagglutination tests with animal sera indicate that fresh collagen-coated cells are sensitive to AGF whereas formalized collagen-coated red blood cells are not (Beard, 1974). Probably, therefore, heat stable antigelatin agglutinators are present in most normal human sera but are not detectable by antiglobulin consumption or by passive haemagglutination using formalized cells. Some of these sera also give precipitin reactions to denatured collagen by Ouchterlony testing.

Although there is general agreement that normal sera react poorly with native as compared with denatured collagen, the serum protein(s) responsible for these reactions have not been identified in most cases. The only difference we have found between test and control human sera (Fig. 4) is that the haemagglutinating titres to denatured collagen are somewhat raised in several 'collagen diseases' (Beard et al., 1976b). It is relevant to comments in the opening paragraphs of this paper that both anticollagen antibodies (Cracchiolo et al., 1975) and collagen-anti-collagen immune complexes (Steffen $e t$ al., 1974) have been identified in synovial tissues and fluids. The results of some other studies of collagen autoantibodies in connective tissue disease are summarized in Table IV.

The antiglobulin consumption test has been used by Steffen's group (Steffen, 1970, 1969; Steffen et al., 1971) to study anticollagen antibodies in a large number of conditions. They have found antibodies in about three-quarters of patients with rheumatoid arthritis, Felty's syndrome, systemic lupus erythematosus, Sjögren's syndrome, and scleroderma, while control sera are largely negative. Of particular interest is their finding of antibodies in $88 \%$ of cases with severe, quickly progressing rheumatoid arthritis and in only $29 \cdot 2 \%$ of cases with slowly progressive disease. Positive reactions could be inhibited equally well with calf and human collagens, and could not be correlated with results of latex and Waaler-Rose testing in the same patients.

Steffen et al. (1973), however, subsequently showed that antinuclear factors were more commonly identified in sera of rheumatoid patients who also had anticollagen antibodies. Similar results have been obtained by Michaeli and Fudenberg (1971), who report haemagglutinating antibodies (using tanned, formalized cells) to denatured collagen in $60 \%$ of the sera of patients with rheumatoid arthritis. Also $20 \%$ of their patients had antibodies to native collagen, while anticollagen antibodies were identified in only $8 \%$ of the control population. The antibodies in several of their sera were found to be IgG by chromatography, and this is also consistent with reported results using the antiglobulin consumption test, which primarily measures IgG antibody.

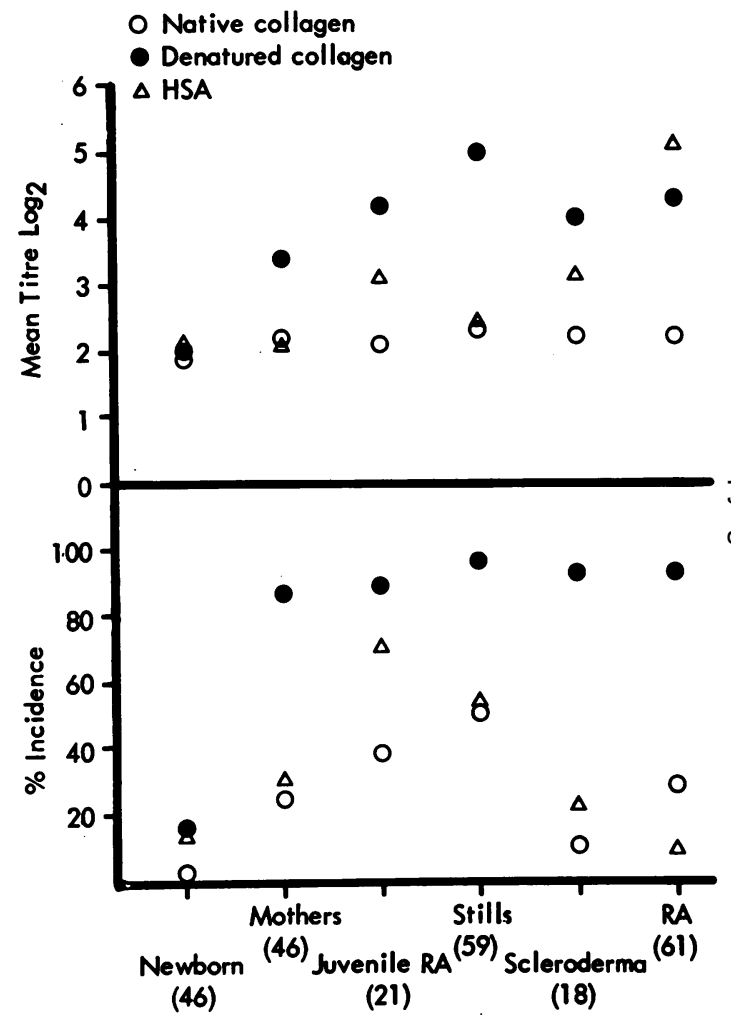

FIG. 4 Haemagglutination of collagen-coated red blood cells by sera from normal people and patients (Conochie and Faulk, unpublished)

Table IV Reported incidence of anticollagen antibodies in patients

\begin{tabular}{|c|c|c|c|c|}
\hline Condition & Positive (\%) & Native & Denatured & Authority \\
\hline Rheumatoid arthritis & $60 \cdot 0$ & - & + & Michaeli and Fudenberg (1974a) \\
\hline Rheumatoid arthritis (severe) & $88 \cdot 0$ & + & - & Steffen (1969) \\
\hline Rheumatoid arthritis (mild) & $29 \cdot 0$ & + & - & Steffen (1969) \\
\hline SLE & $68 \cdot 0$ & + & - & Steffen (1969) \\
\hline Scleroderma & $71 \cdot 0$ & + & - & Steffen (1969) \\
\hline Emphysema & $17 \cdot 0$ & + & - & Michaeli and Fudenberg (1974b) \\
\hline Emphysema & $70 \cdot 0$ & - & + & Michaeli and Fudenberg (1974b) \\
\hline IgA deficiency & $44 \cdot 0$ & + & - & Wells et al. (1973) \\
\hline
\end{tabular}


An unusual group of patients lacking IgA have been studied by Wells et al. (1973). An overall incidence of $44.4 \%$ of these patients had antibodies to native human skin collagen as measured by tanned-cell agglutination, and similar antibodies were found in only $2.5 \%$ of the control population. Although other autoantibodies are often found in patients who lack IgA there was no correlation between the presence of anticollagen antibodies and autoantibodies to $\operatorname{IgG}, \operatorname{IgA}, \operatorname{IgM}$, or antibodies to ruminant proteins. These investigators used tanned, formalized cells and antibodies to denatured collagen were not studied.

Michaeli and Fudenberg (1974a) investigated the class and antigenic specificity of antibodies to denatured human collagen in rheumatoid arthritis and found them to be primarily IgG. Two sera were studied using cyanogen-bromide (CB) fragments of collagen to inhibit the tanned-cell agglutination reaction, and a CB fragment from the $\mathrm{N}$ terminus of the $\alpha_{1}$-chain and a CB fragment from the helical part of the $\alpha_{2}$-chain were found to inhibit.

Specificity for an N-terminal $\alpha_{1}$-peptide helps to explain why some human sera can recognize both native and denatured collagen, because non-helical sites are presumably available in both (Beard et al., 1976b). On the other hand, collagen autoantibodies are known to cross-react between species (Steffen, 1969) and since species cross-reactivity is usually attributed to central sites available only on denatured collagen the inhibitory effect of the CB fragment from the helical part suggests an antidenatured specificity for these sera.

Identical results for $\alpha_{2}$-chain specificity have been obtained by Michaeli and Fudenberg (1974b) in their study of anticollagen antibodies in the sera of 422 patients with emphysema. They found that neither whole $\alpha_{1}$-chain nor $\alpha_{1}$ CB fragments inhibited tanned-cell agglutination, but fragments from either central or $N$-terminal sites in $\alpha_{2}$-chains inhibited haemagglutination.
In addition to serum antibodies, Steffen has claimed that antibodies to collagen may be detected in the synovial fluid from rheumatoid joints by agglutination of collagen-coated red blood cells (Steffen, 1970). In view of the findings of Conochie et al. (1975) the agglutinations obtained were probably not due to anticollagen antibodies but to the presence of glycosaminoglycans. These authors showed that the non-covalent binding between collagen and various polyanions, especially chondroitin-4-sulphate, closely simulates an immunological agglutination, and it seems likely that such substances are present in synovial fluid of the rheumatoid joint.

With regard to reactivity against native and denatured collagen, therefore, human autoantibodies against the latter seem to be well authenticated and to be present in raised titre in some systemic rheumatic diseases and some other chronic conditions which are associated with collagen breakdown. The true incidence of anti-native collagen autoantibodies in health and disease needs further investigation and biochemical characterization of AGF is needed.

Finally, a word about the possible functional role of anti-denatured collagen autoantibodies. Faulk et al. (1975) have shown that collagen is a membrane-bound component of fibroblasts. Exposure of these cells to anticollagen antisera causes patch-and-cap reactions of the membrane collagen analogous to that produced in B-lymphocytes by anti-Ig sera. In addition, Faulk and Temple (1975) have shown that fibroblasts grown in the presence of a rabbit antifibroblast antibody are stimulated to incorporate more radio-labelled proline into TCAprecipitable protein than are control cells grown in the presence of normal rabbit serum. The possibility that one effect of anticollagen antibody might be to stimulate fibroblasts to synthesize and secrete more cell product deserves study. Finally, the possible role of AGF-macrophage interactions in collagen catabolism merits further investigation (Hopper et al., 1976). 